\title{
Cellular Ceramics by Direct Foaming of Emulsified Ceramic Powder Suspensions
}

\author{
Suelen Barg, ${ }^{\dagger}$ Christian Soltmann, Miria Andrade, Dietmar Koch, and Georg Grathwohl \\ Ceramic Materials and Components, University of Bremen, D-28359 Bremen, Germany
}

\begin{abstract}
A new direct foaming method to produce macroporous cellular ceramics using surfactants as foam stabilizers is presented. The technology relies on the transition of a stabilized aqueous ceramic powder suspension containing a homogeneously dispersed alkane or air-alkane phase into cellular ceramics. The stabilization of the powder suspension and the emulsion is realized with particular emphasis on the interaction of both mechanisms providing enduring stability of the system up to high foaming degrees. Anionic, cationic, and nonionic surfactants were studied with their stabilization and foaming effects. The presence and influence of air bubbles was proved to be of negligible importance. Foaming is then provided by the evaporation of the emulsified alkane droplets, leading to the expansion of the emerging foam and giving rise to solids foams with cell sizes from 0.5 to $3 \mathrm{~mm}$ and porosities up to $97.5 \%$ after sintering. The microstructures of these filigree ceramics are stable and rigid with dense struts and uniform distributions of the solid phase and the porosity.
\end{abstract}

\section{Introduction}

$\mathrm{H}$ IGH-performance ceramics with cellular microstructures find their applications in many different fields of modern technologies. Owing to their specific properties such as high permeability, high surface area, high-temperature stability, low weight, and low thermal conductivity, the development of highly porous ceramics has attracted increasing interest in recent years. These applications include filtration of molten metals and hot gases, thermal and acoustic insulation, light-weight structural components, catalytic carriers, support for fuel cells, electrodes, sensors, bioreactors, radiant burners as well as scaffolds for bone replacement. ${ }^{1-6}$

The functions of these advanced materials and components are based on the presence of controlled porosity. This is related to the main porosity parameters as total porosity, pore size distribution, pore morphology, connectivity between the pores, specific surface area, and their effect on mechanical properties. The tailored microstructures required by the specific applications have to be realized by adjusting the synthesis parameters and the processing routes.

The processing method has a decisive influence on the microstructure and the properties of the material. Different manufacture processes have been used to produce porous ceramics with controlled properties. The main processes presently available can be classified into replica, sacrificial template, and direct foaming techniques. The essential features of these methods have been reviewed recently by Studart et $a l^{2}$

The most common process for producing ceramic foams is the replica technique, which consists in the impregnation of a polymeric sponge (typically of polyurethane) with a ceramic slurry or a precursor solution, followed by the removal of excess

J. Halloran — contributing editor slurry, pyrolysis of the polymeric substrate, and finally sintering in an appropriate atmosphere and temperature for solidification of the foam. ${ }^{7,8}$ Therefore, the ceramic foam replicates the original organic polymer structure. This technique allows to produce porous ceramics with cellular porosity and pore sizes ranging from approximately 200 to $3 \mathrm{~mm} .^{9}$ The difficulty of slurry impregnation limits the realization of smaller cell sizes. The struts contain central holes, which result from the burning out of the polyurethane template as well as microcracks and pores. Furthermore, the replication technique generates a large amount of $\mathrm{CO}_{2}$ during firing due to decomposition of organic compounds. ${ }^{7-9}$ Suitable biogenic porous structures have also been used as templates for the realization of cellular ceramics with particular microstructures that could not be produced by other methods. Different techniques have been developed for the replication of wood structures in various ceramic materials. ${ }^{10,11}$

In case of the sacrificial template technique, a fugitive phase that can be removed by a burning, ${ }^{12}$ decomposition, ${ }^{13}$ or evaporation ${ }^{14}$ process is uniformly dispersed in a ceramic precursor. The desired porosity is then obtained as a residue of the sacrificial phase. With this technique, one can achieve pore sizes from 1 to $700 \mu \mathrm{m}$ and porosities from $20 \%$ to $90 \%$. The microstructures obtained by this technique reflect directly the pattern of the sacrificial phase.

In direct foaming techniques, a ceramic suspension is foamed by gas incorporation (physical or chemical blowing); the wet foam is stabilized, dried, and sintered. Extremely high porosities up to $97 \%$ can be obtained. The expenditure for this method is low and its flexibility is high in terms of chemical composition and adjustment of the final microstructure. The key aspects are the stabilization and consolidation mechanisms. Wet foams are thermodynamically unstable systems in which processes like drainage of the liquid phase and gas bubble coarsening lead to foam degradation and final destruction. Drainage corresponds to the flow of the liquid phase due to the gravity effect. Reducing the amount of the liquid phase results in a closer approach of the bubbles, which leads to their coalescence. Diffusion of gas occurs between bubbles of different sizes and consequently different concentrations of gas due to the difference in Laplace pressure between them (Ostwald ripening). ${ }^{2,15-17}$ These mechanisms of foam degradation are driven by the reduction of the Gibbs free energy of the system. It is then of fundamental importance to activate further stabilization effects in order to control the natural evolution of the foamed powder suspensions and to provide adjustment of the cellular ceramic microstructure.

Surfactants can be used as surface-active agents for the stabilization of wet foams. These long-chain amphiphilic molecules adsorb at the gas bubble surfaces with their hydrophilic tail in contact with the aqueous phase. The foaming ability of a surfactant is related to its effectiveness to lower the interfacial energy or the surface tension at the gas-liquid interface. Their chemistry, in terms of molecular weight, polarity, and critical micelle concentration, can significantly influence the emerging microstructure of the foamed suspension. Surfactants are classified according to the hydrophilic group as anionic, cationic, nonionic, and amphoteric. ${ }^{15}$ Ceramic foams stabilized by surfactants are reported to have pore sizes from $35 \mu \mathrm{m}$ up to the mm scale. ${ }^{18-22}$ 
Colloidal particles can also be used as foam stabilizers to produce ultrastable wet foams. ${ }^{17,23-28}$ Recently, Gonzenbach et $a .^{23-26}$ have developed a method that manages the surface modification of highly concentrated colloidal particles in such a way that a high concentration of small air bubbles can be preserved against destabilization. With this method, smaller pore sizes $(10-300 \mu \mathrm{m})$ can be achieved in the cellular ceramic microstructures. Besides the reduction of pore sizes, the particle stabilization method allows straightforward consolidation and drying processes leading also to remarkable compressive strength of the resulting porous ceramics.

A direct foaming process is described in this paper, with an emulsified ceramic powder suspension being conditioned for this purpose by emulsifying a homogeneously dispersed alkane or air-alkane phase in the stabilized aqueous powder suspension. In contrast to the more conventional direct foaming methods where foaming is achieved during stirring by incorporation of air bubbles into the suspension, foaming is provided here by evaporation of the emulsified alkane droplets. This process leads to a time-dependent expansion of the emerging foam in a mold, with the shaping of the cellular part being accomplished in situ during the process. This autonomous foaming process then allows high flexibility in the production of ceramic parts with very high porosities including gradient structures and complex shaping.

Foaming proceeds while the conditions for stabilization are fulfilled for both parts of the system, namely the powder suspension and the alkane emulsion. The rising foam then has to be consolidated before destabilization processes can lead to foam degradation. Because this consolidation process is mainly provided by drying the kinetics of foaming, bubble expansion, foam aging, and drying have to be considered as concurrent processes with their individual dependencies on the parameters of the system and the process. A general description of the direct foaming process has been presented in a previous work. ${ }^{18,19}$ It is then the objective of this paper to identify the parameters controlling the transition from an emulsified suspension to a ceramic foam, in particular, the effects of different surfactants and stabilization factors on the foaming process, the influence of air introduction, and combined effects on the microstructure of the ceramic foams emerging from this process. While the method is described here for alumina foams, this technique may also be applied to other oxide and nonoxide ceramics and even metals depending on the adjustment of dispersion agents and surfactants for the different powder surface chemistries. As surfactants provide highly efficient means to stabilize gas-liquid or liquid-liquid interfaces, their actual charging state is of particular interest for this foaming process, taking into account that cationic and anionic surfactants are expected to act as better foaming agents compared with nonionic surfactants. ${ }^{29}$ Commercially available surfactants are then used for the preparation of emulsified suspensions and tested in terms of foaming ability and foam growth as well as their influence the final microstructure of the ceramic foams.

\section{Materials and Methods}

\section{(1) Materials}

Powder suspensions were prepared using deionized water and $\alpha$ $\mathrm{Al}_{2} \mathrm{O}_{3}$ powder (Alcoa CT $3000 \mathrm{SG}$, Alcoa, Frankfurt, Germany) with an average particle diameter $\left(d_{50}\right)$ of $500 \mathrm{~nm}$ and a specific surface area of $7.5 \mathrm{~m}^{2} / \mathrm{g}$. A low-molecular-weight $(320 \mathrm{~g} / \mathrm{mol})$ polyacrylic acid commercially available as Dolapix CE-64
(Zschimmer \& Schwarz, Lahnstein, Germany) was added as a negatively charged electrosteric dispersion agent to stabilize the suspensions. The effect of anionic, nonionic, and cationic longchain surfactants (Table I) on the stabilization of the alkane and air-alkane bubbles in the emulsions was investigated. The addition of these surfactants had to take into account the $\zeta$ potential and isoelectric point (IEP) of the alumina suspension. Cationic surfactants could only be applied under acidic conditions $(\mathrm{pH} 5.5)$ where the $\zeta$ potential is high, while anionic and nonionic surfactants were used under alkaline conditions $(\mathrm{pH}$ 9.5) where the strong negative $\zeta$ potential was provided by the dispersion agent. pH 5.5 was adjusted by hydrochloric acid $1 \mathrm{~N}$ (Riedel-de Haen, Seelze, Germany).

\section{(2) Preparation of the Alkane Emulsion in the Powder Suspension}

For the production of the cellular ceramics, the first step is the preparation of a stabilized alumina powder suspension. This step is followed by the formation of an emulsion as a homogeneous dispersion of an alkane phase or an alkane phase in combination with air bubbles in the alumina suspension. For this purpose, surfactants as stabilizers and the alkane phase are added after the stabilized alumina suspension is prepared. In case of anionic and nonionic surfactants, the stabilized powder suspensions were prepared as follows: $42 \mathrm{vol} \%$ of alumina powder was slowly added to deionized water containing Dolapix CE-64 (0.74 wt\% related to alumina) as a dispersion agent under vigorous mixing. Dispersion and homogenization was carried out in a laboratory mixer (Dispermat LC, VMA Getzmann $\mathrm{GmbH}$, Reichshof, Germany) with a $30 \mathrm{~mm}$ dispersing tool operating at a mixing velocity of $2500 \mathrm{rpm}$ for $20 \mathrm{~min}$. In former experiments, ${ }^{18,19}$ the optimal powder dispersion was investigated and attributed to the efficiency of this electrosteric dispersion agent.

For the production of foams stabilized with cationic surfactants, the suspensions were prepared at $\mathrm{pH} 5.5$ with $\mathrm{HCl}$ where the $\zeta$ potential is found to be sufficiently high for stabilization of the alumina suspension. The other parameters are the same as those described for anionic and nonionic surfactants. Afterwards, the suspensions were subjected to deaeration to remove undesired entrapped bubbles. This procedure was performed in a container under reduced pressure $(5 \mathrm{kPa})$.

Subsequently, $5.5 \mathrm{vol} \%$ heptane was added to the ceramic suspension, together with $0.83 \mathrm{vol} \%$ of different surfactants (Table I), thereby defining $V_{\mathrm{i}}$ as the initial volume of the combined system. Mixing is then achieved by mechanical stirring for $2.5 \mathrm{~min}$ at $2500 \mathrm{rpm}$. This preparation step of the alkane emulsion in the powder suspension is accompanied by air incorporation into the system if the mixing procedure occurs in ambient air. This happens because the surfactants decrease the gas-liquid surface tension and a first volume increase is achieved by this process step. This volume increase of the emulsified suspensions during mechanical stirring was determined by the foaming ability coefficient $F_{\mathrm{a}}=V_{\mathrm{f}} / V_{\mathrm{i}}$, with $V_{\mathrm{f}}$ describing the volume of the emulsion after air incorporation by mechanical stirring for $2.5 \mathrm{~min}$.

The suspensions containing the different surfactants were emulsified in ambient air but also under reduced pressure at room temperature to avoid the abundant incorporation of air bubbles. A moderately reduced pressure of $10 \mathrm{kPa}$ was chosen with respect to the evaporation of heptane, which has a vapor pressure of $4.6 \mathrm{kPa}$ at $20^{\circ} \mathrm{C}$.

Table I. Properties of the Surfactants Used as Foaming Agents

\begin{tabular}{lllcl}
\hline Type & Commercial notation & Producer & Molecular weight $(\mathrm{g} / \mathrm{mol})$ & Molecular formula \\
\hline Anionic & Lutensit AS 2230 & BTC & 671.3 & $\mathrm{C}_{12} \mathrm{O}_{\left(\mathrm{CH}_{2} \mathrm{CH}_{2} \mathrm{O}\right)_{2} \cdot 5 \mathrm{SO}_{3} \mathrm{Na}}$ \\
Cationic & B8879 & Sigma & 448.1 & $\mathrm{C}_{27} \mathrm{H}_{42} \mathrm{ClNO}_{2}$ \\
Nonionic & Lutensol ON80 & BASF & 358 & $\mathrm{Cl}_{18} \mathrm{H}_{37}\left(\mathrm{OCH}_{2} \mathrm{CH}_{2}\right)_{2} \mathrm{OH}$ \\
\hline
\end{tabular}




\section{(3) Foam Formation, Setting, and Sintering}

The emulsified suspensions were poured in quantities of 12 and $26 \mathrm{~g}$ into plastic round molds with diameters of 50 and $80 \mathrm{~mm}$, respectively, and a height of $15 \mathrm{~mm}$. The following autonomous foaming process was realized in a clima chamber (Terra Universal, Fullerton, CA) under controlled temperature and humidity $\left(23^{\circ} \mathrm{C}\right.$ and $\left.65 \%\right)$. Foaming proceeds as a consequence of the evaporation of the alkane phase resulting in the growth of the stabilized alkane bubbles and in a volume increase of the foam (Fig. 1). The resulting foamed green body possesses a tight cylindrical form with a cross section corresponding to the mold. The foaming growth was evaluated under controlled temperature and humidity conditions dependent on the surfactant used and the presence of air bubbles during $4 \mathrm{~h}$. The growth of the foam with time was calculated by $\left(h_{\mathrm{t}}-h_{\mathrm{o}}\right) / h_{\mathrm{o}}$ where $h_{\mathrm{o}}$ is the initial height of the freshly poured samples and $h_{\mathrm{t}}$ is the height of the foams after a given time. After the consolidation, the alumina foams were dried and sintered at $1550^{\circ} \mathrm{C}$ for $2 \mathrm{~h}$.

\section{(4) Characterization Methods for Suspensions, Emulsified Suspensions, and the Sintered Foams}

Zeta potential experiments (DT-2000, Dispersion technology Inc., Bedford Hills, NY) were undertaken with alumina suspensions (5 vol\%), with and without Dolapix CE-64 $(0.74 \%)$ as a dispersion agent, in order to determine the stabilization state of the suspensions.

Immediately after mechanical stirring, samples of the emulsified suspensions were transferred into closed Quartz cells (Hellma, Müllheim/Baden, Germany) or opened recipients (when the investigation of the bubble growth was intended) and subsequently analyzed by fluorescence microscopy. The alkane phase was dyed with Pyrene (Fluka, Steinheim, Germany), making the
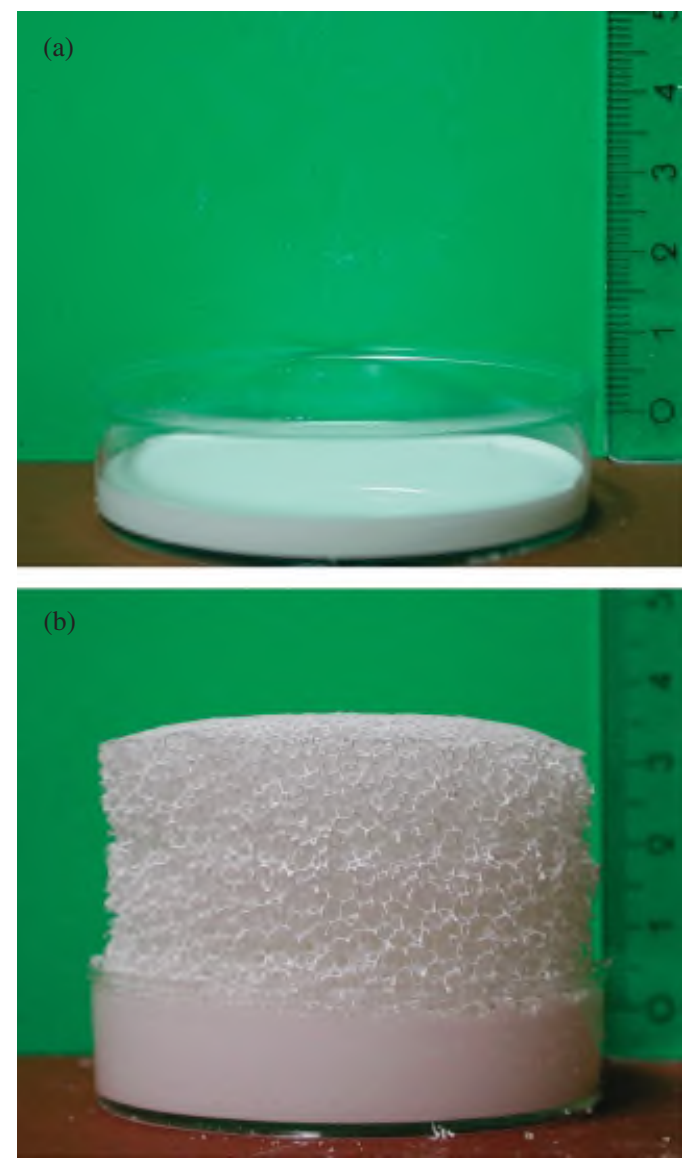

Fig. 1. Autonomous foaming process: (a) emulsified alumina powder suspension freshly poured into the mold; (b) wet foam formed after $3 \mathrm{~h}$ at $23^{\circ} \mathrm{C}$ and $45 \%$ humidity. alkane droplets fluorescent at an emission wave length $\lambda_{\mathrm{Em}}$ of $375 \mathrm{~nm}$. With this technique, it was possible to distinguish the alkane droplets and air-alkane bubbles from the alumina suspension. Droplet and bubble size distributions were measured in closed emulsified suspensions composed of $0.83 \mathrm{vol} \%$ anionic surfactant and $5.5 \mathrm{vol} \%$ heptane produced under reduced pressure and in ambient air. For each condition, 100 droplets or bubbles were individually measured for statistical analysis with the use of Axio Vision LE image analysis program.

The cellular network and the microstructure of the sintered ceramic foams were analyzed by scanning electron microscopy (Camscan 24, Cambridge, England) as well as by computer Xray tomography ( $\mu \mathrm{CT} 40$ Scanco medical, Bassersdorf, Switzerland). Therefore, ceramic foams were cut and cell size distributions were directly obtained from planar sections. As the foams were rigid enough and no embedding was necessary, the windows were easily distinguished from the cell architecture. Cell size, window opening, and strut thickness were individually measured with the help of an image analysis program (AnalySIS). For each condition, two regions per sample in two samples were chosen and digital images were taken for statistical analysis. The volumetric density $\rho_{\mathrm{v}}$ of the foams was determined from the mass and dimensions of the sintered bodies. The porosity $P$ was then calculated as $P=1-\rho_{\mathrm{v}} / \rho_{\mathrm{t}}$, with $\rho_{\mathrm{t}}\left(3.9 \mathrm{~g} / \mathrm{cm}^{3}\right)$ corresponding to the theoretical density of alumina.

\section{Results and Discussion}

\section{(1) Stabilization of the System}

For successful foaming of the system, the suspensions and the emulsions had to be sufficiently homogenized and stabilized as described in Section II(2). The effects of the suspension stabilization agent and the foaming agents are taken into account in a way to control their interaction and consequently to prevent the destabilization and coagulation of the system. Therefore, in case of anionic and nonionic surfactants, the alumina suspension was negatively stabilized while the alumina particles were positively charged when the emulsion was stabilized by cationic surfactants. The $\zeta$ potential curve of the alumina suspension in Fig. 2 shows that at $\mathrm{pH} 5.5$ (by which the suspension is prepared), the particle surfaces are positively charged which enables the use of the cationic surfactant. On the hand side, the adsorption of $\left(-\mathrm{COO}^{-}\right)$ anions on the alumina surface shifts its IEP to 4.65 , resulting in a negative surface charge of the alumina particles at $\mathrm{pH} 9.5$, by which these suspensions are prepared. In this case, the suspension stabilization is adequate for the use of anionic and nonionic foaming agents. In all cases, the suspensions and emulsions were efficiently prepared without coagulation in the systems.

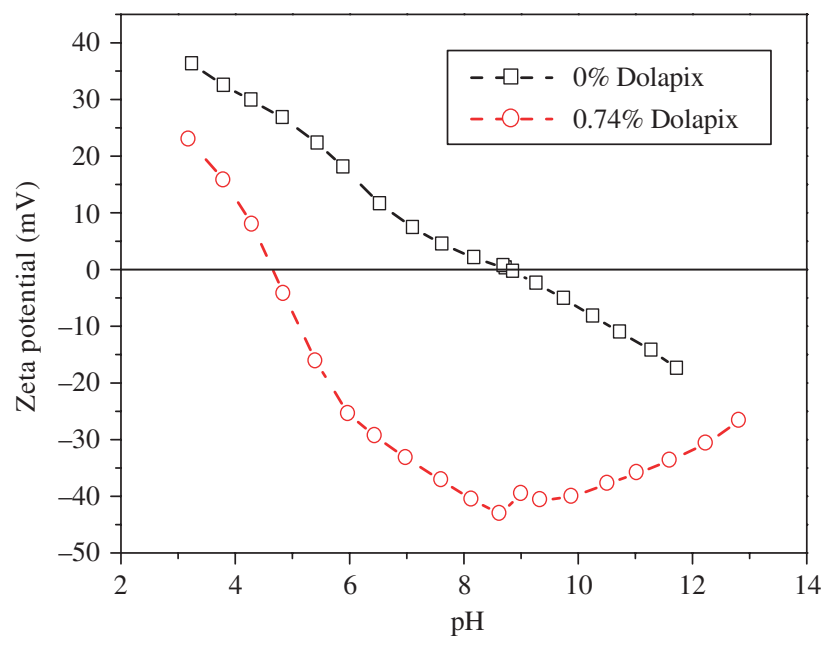

Fig. 2. Zeta potential of alumina suspensions as a function of $\mathrm{pH}$ without and with a negatively charged dispersion agent Dolapix CE-64. The suspensions were prepared with $5 \mathrm{vol} \%$ of alumina. 


\section{(2) Emulsification}

The emulsified suspensions closed in quartz cells were analyzed immediately after mechanical stirring under fluorescence microscopy. The size distributions of the alkane droplets and the air-alkane bubbles in the emulsified suspensions are presented in Fig. 3. The alkane droplet size distribution produced under reduced pressure in the emulsified ceramic suspension ranges from 2.5 to $6 \mu \mathrm{m}$, with a mean droplet size $\left(d_{50}\right)$ of $4.13 \mu \mathrm{m}$. When ambient air is present during the emulsification process, the alkane distribution is modified and, besides the small alkane droplets, larger alkane-air bubbles are observed up to $40 \mu \mathrm{m}$. This broadening is caused by stirring under ambient air, leading to a first foaming step as described later (Fig. 6).

\section{(3) The Foaming Process}

The transition of the emulsified ceramic suspension to the wet foam starts as soon as the emulsification process is completed. The bubble size evolution of an emulsified suspension containing $5.5 \mathrm{vol} \%$ heptane and $0.83 \mathrm{vol} \%$ anionic surfactant emulsified in ambient air is shown in Fig. 4 using fluorescence microscopy. Foaming is investigated here in a model experiment leading to images that illustrate the foaming progress of the emulsified suspension in an opened recipient. The system contains small heptane droplets and larger air-heptane bubbles at the start of foaming as indicated in Fig. 4(a). The transformation of the alkane phase from liquid to gas directly after the mixing process is accompanied by the expansion of bubbles due to its high vapor pressure (Fig. 4(b)). Simultaneous with bubble expansion, other physical processes assist the bubble growth, decreasing thereby the free energy of the system. Some small heptane bubbles disappear due to gas diffusion from smaller to larger bubbles as a result of the Laplace pressure gradient between them (Ostwald ripening). The number of bubbles is reduced while their size increases. Other bubbles coalesce and grow by thinning and breaking of the film surrounding them. These effects can be observed from the recorded images resulting in a rapid bubble size increase. After 3 min (Fig. 4(c)) under the microscope, the plateau borders are well defined and the foaming process in this model sample approaches its completion.

The setting of the foam is assisted by advancing drainage processes at plateau borders and thin films, evaporation of the liquid phase (drying), and consequent rupture of the bubble membranes. Consequently, the concurrence between the bubble expansion kinetics and the setting of the structure controls the foam cell size. Moreover, parameters like surfactant nature,

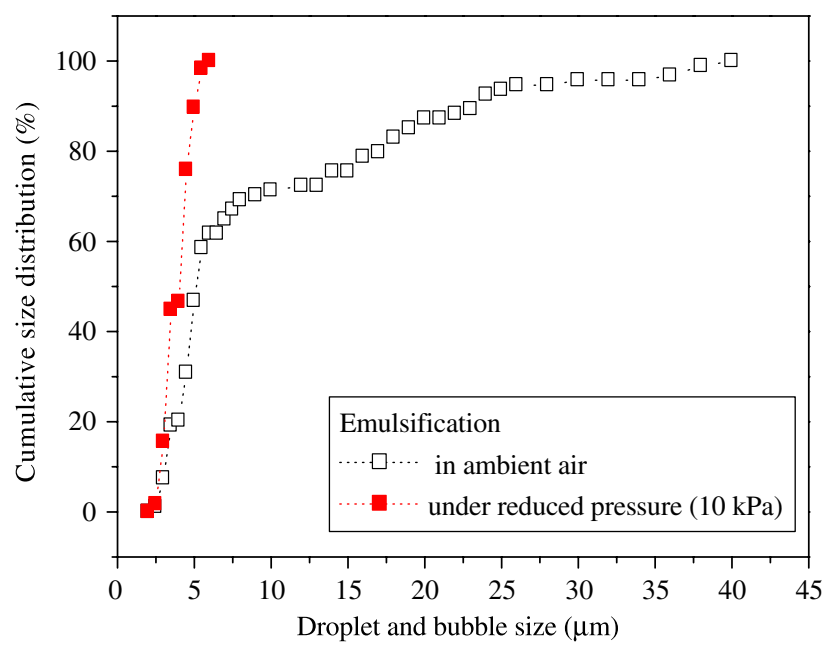

Fig. 3. Effect of partial pressure during mixing $(2.5 \mathrm{~min})$ on the alkane droplet and air-alkane bubble size distribution in emulsified alumina suspensions containing $5.5 \mathrm{vol} \%$ heptane and $0.83 \mathrm{vol} \%$ anionic surfactant. Size measurement was enable by fluorescence microscopy under closed recipient conditions. vapor pressure and content of the vaporizing components, temperature, and humidity also influence these mechanisms. ${ }^{18,19}$

The foaming process proceeds continuously from the top to the bottom of the poured suspension. While alkane droplets in the top region evaporate and grow, new droplets are simultaneously starting the foaming process in the lower parts until the whole volume of the emulsion is converted into a stable foam. Three stages of the foaming process can be recognized as illustrated in Fig. 5. The emulsified suspension is represented by stage (a). The alkane droplets located at the upper parts of the emulsion start evaporating, giving rise to spherical bubbles present at stage (b). The formation of polyedric structures characterized by thin films at the interfaces of touching cells and the so-called plateau borders at the intersection of three interfacial films is first reached in the top layer and defines stage (c). This stage represents the transition of the growing to the stable foam and corresponds to the situation presented in Fig. 4(c).

\section{(4) Influence of Surfactants on the Foaming Process and the Microstructure}

The foaming ability coefficient $F_{\mathrm{a}}$ of the three different surfactants used is shown in Fig. 6. The cationic surfactant shows a higher ability of air stabilization in the system, followed by anionic and nonionic surfactants. Primarily, the ability of a foaming agent to incorporate large quantities of air into the emulsified suspension depends on the surfactant's effectiveness in reducing the surface tension of the system.
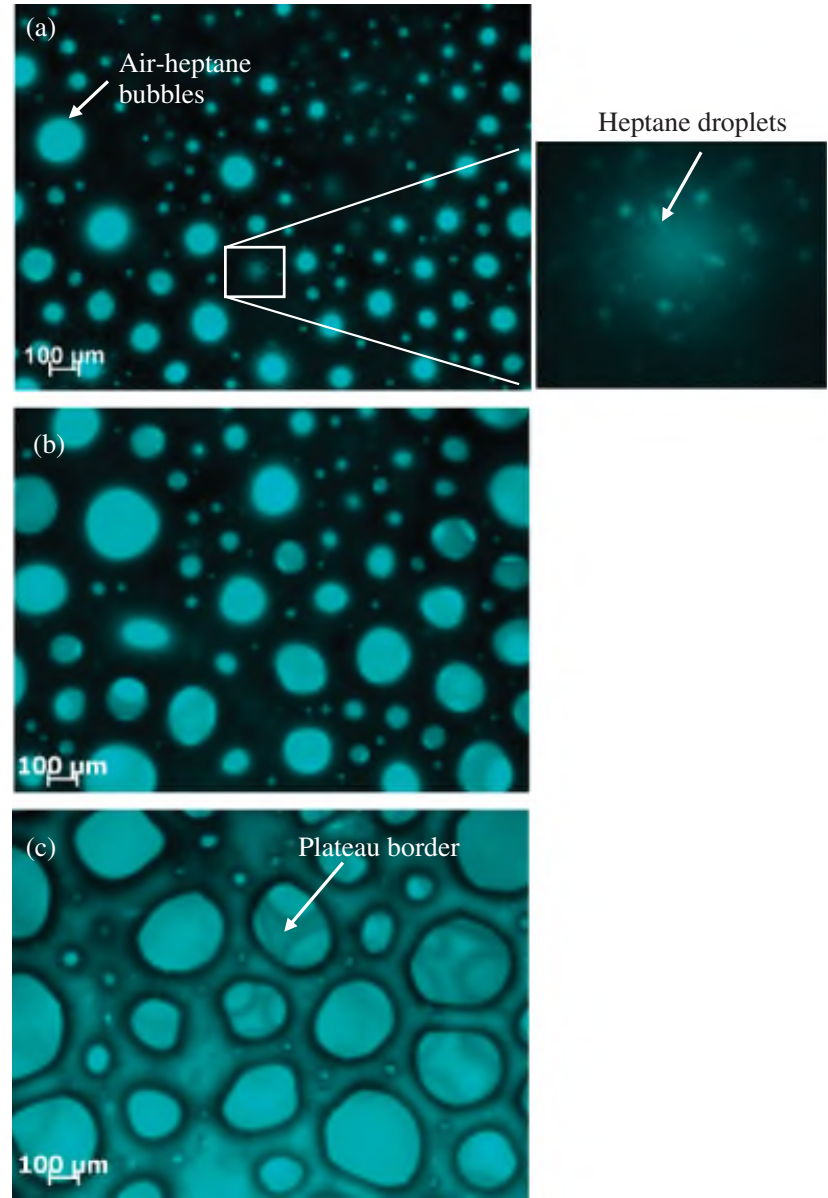

Fig. 4. Bubble growth in alumina powder suspension emulsified (5.5 vol $\%$ heptane and $0.83 \mathrm{vol} \%$ anionic surfactant) in ambient air as illustrated via fluorescence microscopy. (a) Samples freshly poured in an opened recipient; (b) after $1 \mathrm{~min}$ and (c) after $3 \mathrm{~min}$. The inset in (a) shows the small alkane droplets. The larger dispersoids correspond to air-alkane bubbles. In (c), the plateau borders can be seen. 


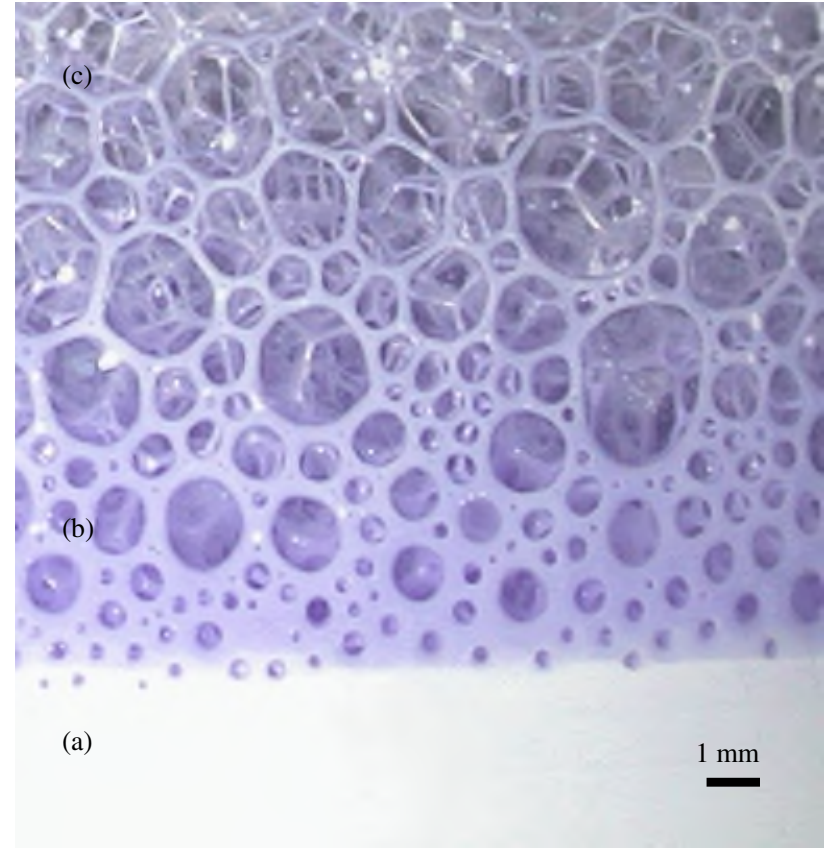

Fig. 5. The three stages of the foaming process of an emulsified ceramic powder suspension: (a) alkane emulsion in the powder suspension; (b) transition of emulsion to wet foam; and (c) formation of a polyhedral structure (transition to stable foam).

After pouring the emulsified suspension into the mold, the foaming process starts immediately as being driven by the autonomous evaporation of the alkane phase. As shown in Fig. 7, the foaming rate is higher in case of the anionic surfactant, followed by the cationic and nonionic surfactants if the emulsion is prepared under reduced pressure (Fig. 7(a)) or in ambient air (Fig. 7(b)), leading to the incorporation of air bubbles.

The foams emulsified under reduced pressure grow at lower foaming rates at the beginning that increase with time (Fig. 7(a)). For the foams emulsified in ambient air, the opposite effect takes place, with higher foaming rates at the initial stage being reduced during the process (Fig. 7(b)). Air bubbles present at the start of foaming may be effective in accelerating the autonomous foaming process in its early stage because preexistence of gas-liquid interfaces is provided in this case.

The lowest foaming rates are observed in the systems with nonionic surfactants, the foam growth being defined as $\Delta h / h_{\mathrm{o}}$, with the initial height $h_{\mathrm{o}}$ of the suspension level in the mold (Fig. 7). After a rather low foam growth of about $150 \%$, the foaming process fades away in nonionically stabilized suspensions emulsified in ambient air, while the other samples,

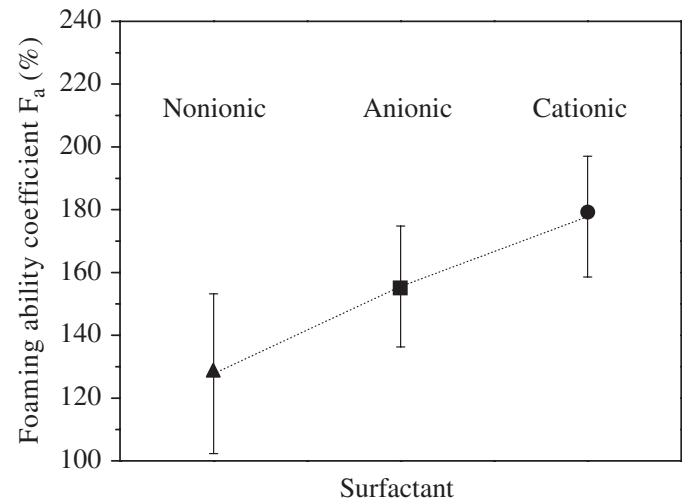

Fig. 6. Foaming ability of emulsified alumina suspensions containing $5.5 \mathrm{vol} \%$ heptane and $0.83 \mathrm{vol} \%$ nonionic, anionic, or cationic surfactants mechanically stirred in ambient air for $2.5 \mathrm{~min}$ at $2500 \mathrm{rpm}$.
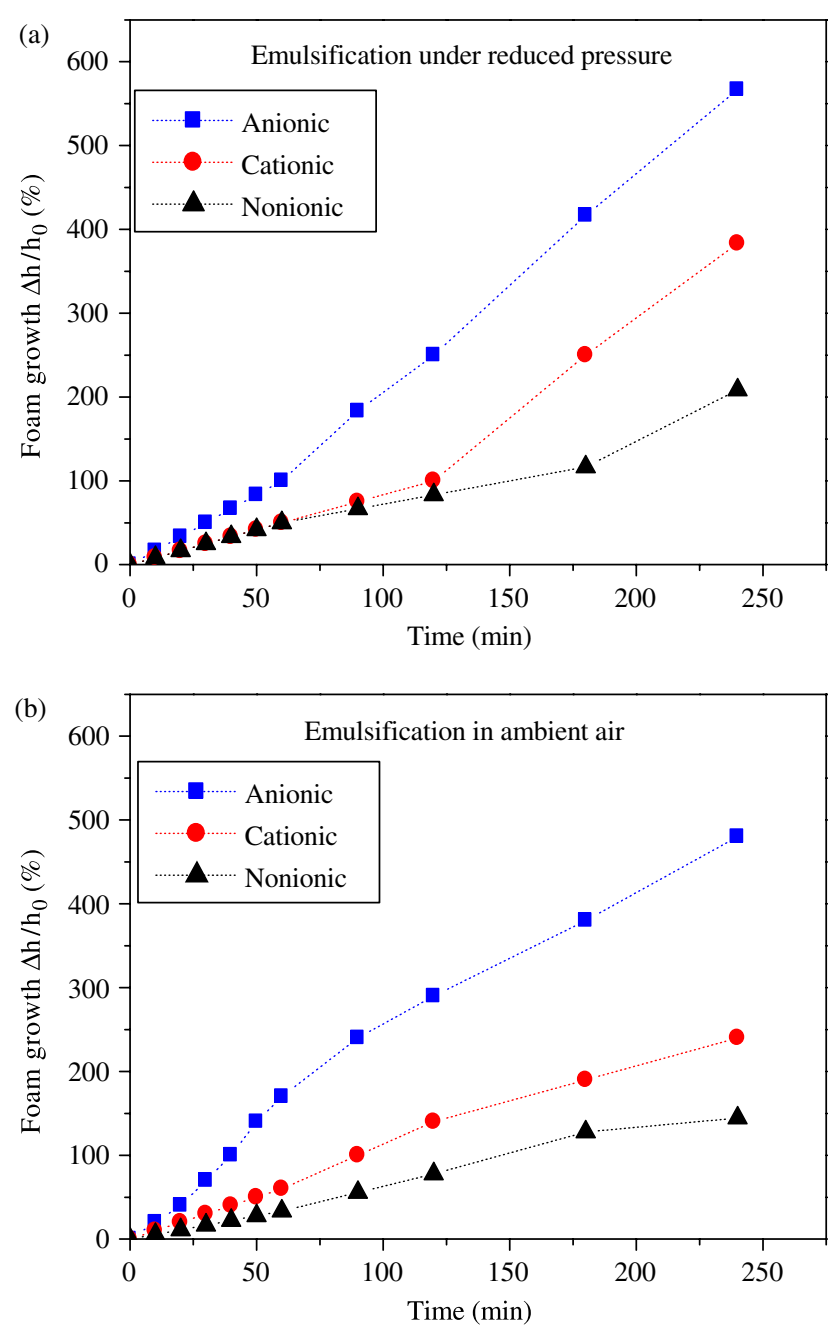

Fig. 7. Autonomous foaming of emulsified alumina suspensions prepared with anionic, cationic, and nonionic surfactants and $5.5 \mathrm{vol} \%$ heptane in air ambient (a) and under reduced pressure, $10 \mathrm{kPa}$ (b). $h_{\mathrm{o}}$ is the initial height of the emulsified suspension after being poured into the mold.

in particular, the anionically stabilized systems, revealed the fact that the foaming process is not completed after $4 \mathrm{~h}$; in contrast, foam growth, albeit with differing foaming rates, is still continuing and leads in the system with the highest foamability (anionic surfactant, emulsification under reduced pressure) to a

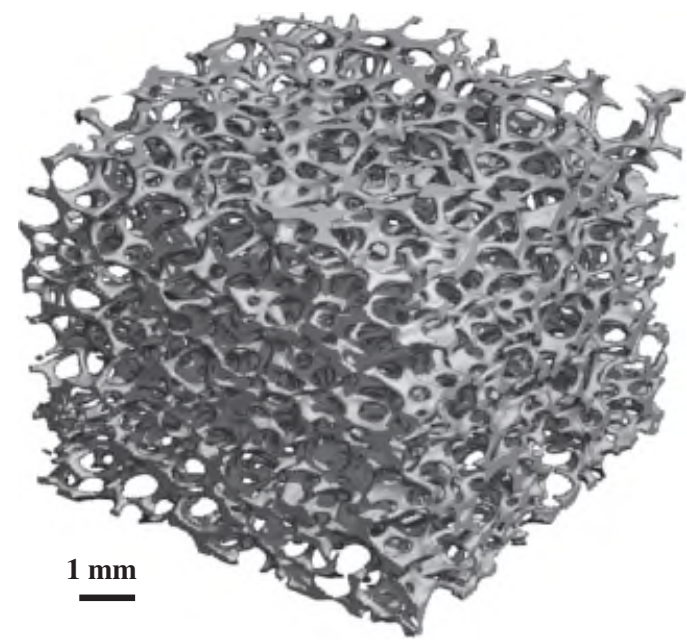

Fig. 8. $\mu \mathrm{CT}$ analysis of cellular alumina produced from powder suspension emulsified (5.5 vol\% heptane and $0.83 \mathrm{vol} \%$ nonionic surfactant) under reduced pressure $(10 \mathrm{kPa})$. (Edda Stern-University of Erlangen). 

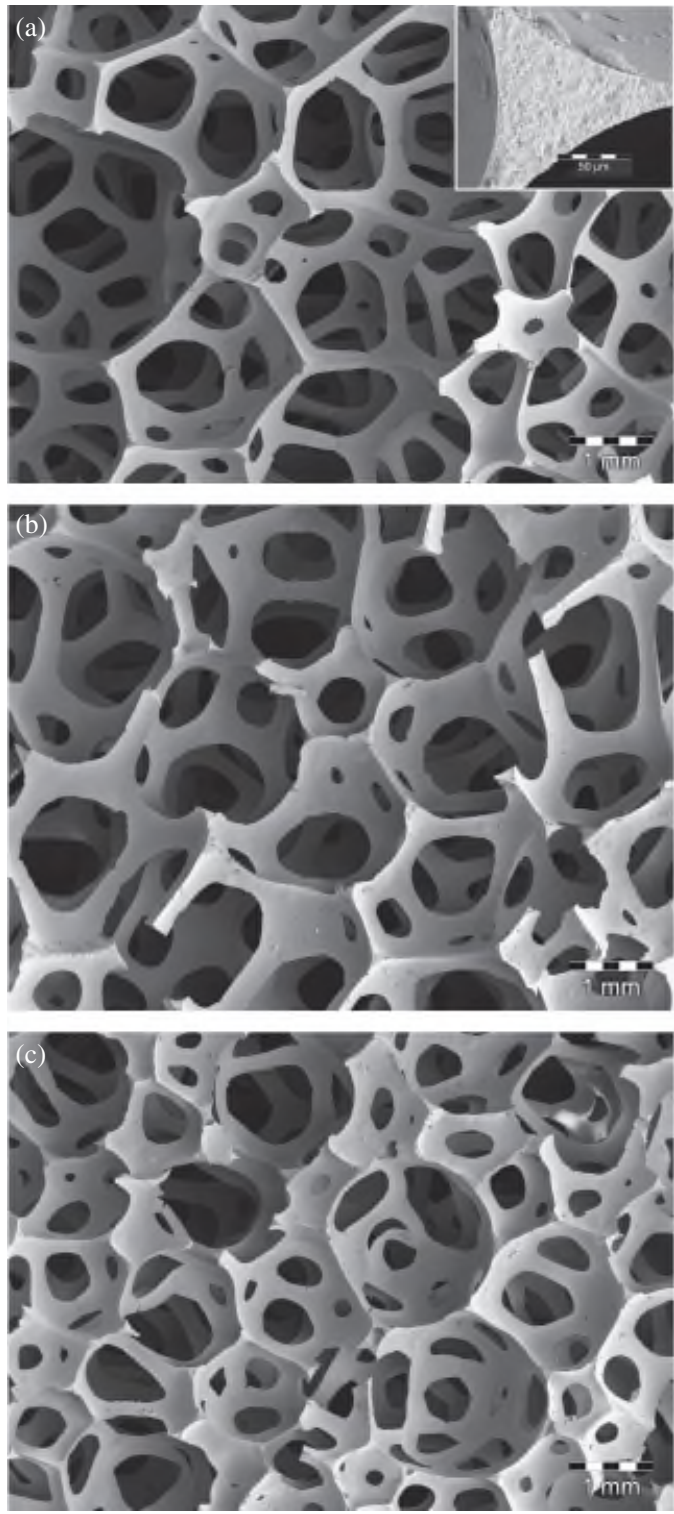

Fig.9. Macrostructures of cellular alumina produced from powder suspensions containing $5.5 \mathrm{vol} \%$ heptane with addition of anionic (a), cationic (b), and nonionic (c) surfactants emulsified under reduced pressure $(10 \mathrm{kPa})$. The foams were formed at $23^{\circ} \mathrm{C}$ and $65 \%$ humidity and sintered at $1550^{\circ} \mathrm{C}$ for $2 \mathrm{~h}$. The inset in (a) shows the fracture surface of a single dense strut.

very high foam growth beyond $550 \%$ after $4 \mathrm{~h}$ of foaming. The curves in Fig. 7 could not be extended to a longer duration beyond $4 \mathrm{~h}$ although a further linear progress of the foam growth is suggested by the slope of the curves. The reason for this can be seen in the macroscopic instability and the upcoming nonuniformity of the shape of the foamed body; reliable determination of further foam growth is then not possible anymore. It also has to be noticed that the samples with the highest foam growth represent a very high porosity in the range of $90 \%$, approaching the physical limit of the foamability of such powder suspensions. If it is possible to transform these wet foams to ceramic cellular structures by sintering, extremely high porosities beyond $95 \%$ are reached under the assumption of zero shrinkage.

The foaming results of Fig. 7 reveal the fact that the anionically stabilized emulsion represents the optimal condition for effective foaming processes of the alumina suspensions. This result then also yields the suitable state and interaction of the powder suspension stabilized by the negatively charged dispersion agent with the anionically stabilized emulsion, thereby favoring the enduring stability of the whole system during the

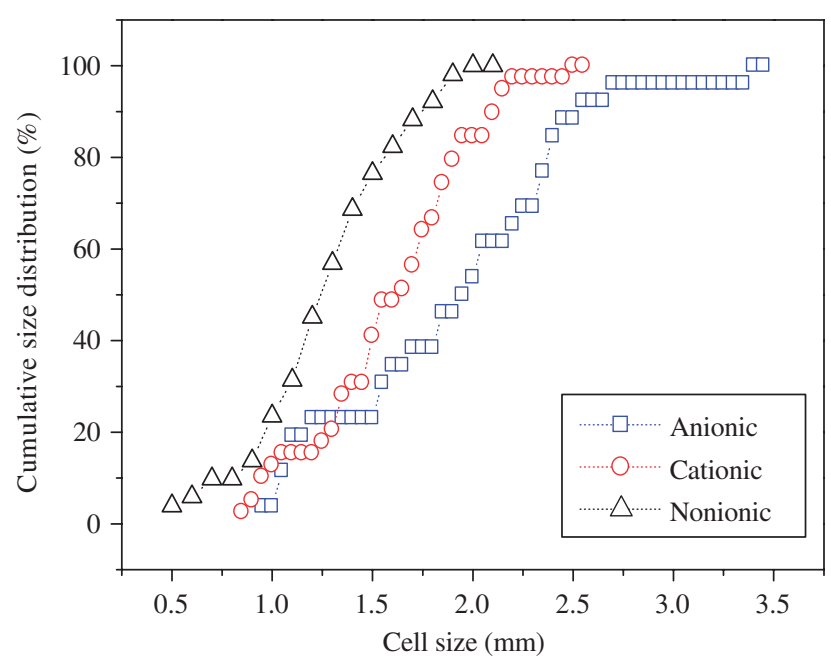

Fig. 10. Cell size distributions of cellular alumina produced from powder suspensions containing $5.5 \mathrm{vol} \%$ heptane with addition of anionic, cationic, or nonionic surfactants emulsified under reduced pressure (10 $\mathrm{kPa}$ ). The foams were formed at $23^{\circ} \mathrm{C}$ and $65 \%$ humidity and sintered at $1550^{\circ} \mathrm{C}$ for $2 \mathrm{~h}$.

most effective foaming procedure. The actual task to provide structural stability during foaming has to be guaranteed by the cell walls of the emerging foam. Their function in providing undamaged thin barriers between the growing gas bubbles depends on both their strength and resistance against viscous flow. It is obvious that these membranes fulfill their tasks in a most impressive way when the powder suspension is foamed to such high porosity levels.

The microstructure of the sintered foams $\left(1550^{\circ} \mathrm{C}, 2 \mathrm{~h}\right)$ is characterized by high porosities between 93 and $97.5 \mathrm{vol} \%$ uniformly distributed throughout the sample with numerous interconnections between the individual cells. Figure 8 gives an impression of a cellular ceramic part produced with a nonionic surfactant under reduced pressure as a $\mu \mathrm{CT}$-picture. Microstructural details of the foams produced by anionic, cationic, and nonionic surfactants under reduced pressure are presented in Fig. 9 including the fracture surface of a single strut under higher magnification. The homogeneously sintered microstructure of the strut without any pores or voids is illustrated. The high degree of foaming in the anionically stabilized system (Fig. 9(a)) turns out as higher porosities and larger cell sizes compared with the other systems (Figs. 9(b) and (c)). This is also quantitatively described in Fig. 10 where cell sizes from 0.5 to $3.5 \mathrm{~mm}$ are shown with their distributions for the systems investigated. It is also noticeable that more spherical cells and smaller cell windows are caused by the nonionic surfactant, while the structure of the anionically stabilized sample approaches the final cellular state of polygonization.

The foamability and final cell size of the sintered foam are mainly attributed to the processes of bubble expansion and coalescence taking place in the wet foams. These processes occur at significantly faster rates in the anionic surfactant-based foams. Rapid bubble expansion to high foaming degrees is accompanied by the reduction of the liquid film thickness, leading finally to thinner struts, and larger cell and window sizes.

While the final morphology and mean cell size of the foams produced in ambient air do not show relevant difference from the foams produced under reduced pressure, a slightly larger dispersion in the cell size distribution is observed under ambient air conditions. Therefore, the incorporation of air into the system changes the foaming rate and slightly decreases the homogeneity in the cell size distribution, which was already demonstrated by the droplet size distribution (Fig. 3). In other words, the foaming process is effective with or without the incorporation of air; this parameter has only limited influence on the foaming degree and the final homogeneity of the foams. 
The foams produced in this work present a rather uniform pore size distribution in the vertical as well as in the horizontal direction. However, as foaming is a time-dependent process, gradients in porosity and pore size distribution can be realized by adjusting the foaming conditions and the shape and dimensions of the foamed body.

\section{Conclusions}

Emulsions containing a homogeneously dispersed alkane or an air-alkane phase in a stabilized aqueous ceramic powder suspension were efficiently prepared and stabilized. With the processing route based on the transition of the emulsified suspension to cellular ceramics, it is possible to realize interconnected structures with cell sizes from 0.5 to $3 \mathrm{~mm}$ and porosities up to $97.5 \%$.

Foaming rate and ability are controlled by the type of longchain surfactants used as a foaming agent. The autonomous foaming process proceeds at faster rates in the anionic surfactant-based system, resulting in foams containing thinner struts, and larger cell and window sizes. The effective stabilization mechanisms of both the powder suspension and the alkane emulsion provide in their mutual interaction a suitable base favoring enduring stability of the system up to extremely high foaming degrees.

The incorporation of air into the system increases the foaming rate in the early stage; some broadening of the droplet and cell size distribution is then observed without strongly affecting the overall foaming degree compared with foaming under reduced pressure.

The process described here can also be extended to other oxide and nonoxide ceramic as well as metallic powders. Corresponding with the large variation of structural parameters obtainable by this method, numerous applications of the cellular ceramics as filters for the metal casting industry, catalytic supports, pore burners, matrix for immobilized microorganisms, and scaffolds for tissue engineering are envisaged.

\section{Acknowledgments}

The authors are grateful to DFG for enabling this work within the frame of the Graduate school PoreNet. The contribution of Dr. S. Blindow to the fluorescence microscopy experiments realized at the Bioceramics group, University of Bremen, as well as the $\mu$-CT analysis by Dr. E. Stern, University of Erlangen, are also gratefully acknowledged.

\section{References}

${ }^{1}$ M. Scheffler, and P. Colombo (Eds.), Cellular Ceramics: Structure, Manufacturing, Properties and Application. Wiley-VCH, Weinheim, 2005, p. 645.

${ }^{2}$ A. R. Studart, U. T. Gonzenbach, E. Tervoort, and L. J. Gauckler, "Processing Routes to Macroporous Ceramics-A Review," J. Am. Ceram. Soc., 89 [6] 1771-89 (2006)

${ }^{3}$ A. Reitzmann, F. C. Patcas, and B. Kraushaar-Czarnetzki, "Keramische Schwämme-Anwendungspotenzial monolitischer Netzstrukturen als katalytische Packungen," Chem. Ing. Technol., 78, 885-98 (2006).

${ }^{4}$ L. J. Gauckler, M. M. Waeber, C. Conti, and M. Jacobduliere, "Ceramic Foam for Molten-Metal Filtration," J. Metals, 37 [9] 47-50 (1985).
${ }^{5}$ Q. Z. Chen, K. Rezwan, D. Armitage, S. N. Nazhat, and A. R. Boccaccini, "The Surface Functionalization of 45S5 Bioglass -Based Glass-Ceramic Scaffolds and its Impact on Bioactivity," J. Mater. Sci.: Mater. Med., 17 [11] 979-87 (2006).

${ }^{6}$ Q. Z. Chen, I. D. Thompson, and A. R. Boccaccini, "45S5 Bioglasss-Derived Glass-Ceramic Scaffolds for Bone Tissue Engineering," Biomaterials, 27, 2414-25 (2006)

${ }^{7}$ P. Colombo and J. R. Hellmann, "Ceramic Foams from Preceramic Polymers," Mater. Res. Innovat., 6, 260 (2002).

${ }^{8}$ J. Saggio-Woyansky, C. E. Scott, and W. P. Minnear, "Processing of Porous Ceramics," Am. Ceram. Soc. Bull., 71 [11] 1674-82 (1992).

${ }^{9}$ S. N. Jayasinghe and M. J. Edirisinghe, "A Novel Method of Forming Open Cell Ceramic Foam,” J. Porous Mater., 9, 265 (2002)

${ }^{10} \mathrm{C}$. R. Rambo and H. Sieber, "Novel Synthetic Route to Biomorphic $\mathrm{Al}_{2} \mathrm{O}_{3}$ Ceramics," Adv. Mater., 18 [8] 1088-91 (2005).

${ }^{11}$ J. Cao, C. R. Rambo, and H. Sieber, "Manufacturing of Microcellular, Biomorphous Oxide Ceramics from Native Pine Wood," Ceram. Int., 30, 1967-70 (2004).

${ }^{12}$ P. Colombo, E. Bernardo, and L. Biasetto, "Novel Microcellular Ceramics from a Silicone Resin," J. Am. Ceram. Soc., 87 [1] 152-4 (2004).

${ }^{13}$ H. Schmidt, D. Koch, G. Grathwohl, and P. Colombo, "Micro-Macro Porous Ceramics from Preceramic Precursors," J. Am. Ceram. Soc., 84, 2252-5 (2001).

${ }^{14}$ D. Koch, L. Andresen, T. Schmedders, and G. Grathwohl, "Evolution of Porosity by Freeze Casting and Sintering of Sol-Gel Derived Ceramics," J. Sol-Gel Sci. Technol., 26, 149-52 (2003).

${ }^{15}$ L. L. Schramm, Emulsions, Foams, and Suspensions: Fundamentals and Applications. Wiley-VCH, Weinheim, 2006.

${ }^{16}$ J. K. Park, J. S. Lee, and S. I. Lee, "Preparation of Porous Cordierite Using Gelcasting Method and its Feasibility as a Filter," J. Porous Mater., 9, 203 (2002).

${ }^{17}$ B. S. Murray and R. Ettelaie, "Foam Stability: Proteins and Nanoparticles," Curr. Opin. Colloid Interf. Sci., 9, 314 (2004).

${ }^{18}$ O. Lavrentyeva and G. Grathwohl, "Zellularkeramik aus autarken Schäumungsprozessen keramischer Suspensionen, Teil 1," Keram. Zeitschr., 2 88-93 (2007)

${ }^{19}$ O. Lavrentyeva and G. Grathwohl, "Zellularkeramik aus autarken Schäumungsprozessen keramischer Suspensionen, Teil 2," Keram. Zeitschr., 4 260-5 (2007)

${ }^{20}$ O. Lavrentyeva, M. Jeske, C. Soltmann, D. Koch, and G. Grathwohl, "Verfahren zur Herstellung von anorganischen Schäumen, danach hergestellter Schaum und Verwendung desselben"; Patent Registration 102005039774.3 23.8.2005.

${ }^{21}$ M. Fuji, T. Kato, F. Zhang, and M. Takahashi, "Effects of Surfactants on the Microstructure and Some Intrinsic Properties of Porous Building Ceramics Fabricated by Gelcasting," Ceram. Int., 32, 797 (2006).

${ }^{22}$ S. N. Tan, D. Fornasiero, R. Sedev, and J. Ralston, "The Role of Surfactant Structure on Foam Behaviour," Colloids Surf. A: Physicochem. Eng. Aspects, 263, 233 (2005).

${ }^{23}$ U. T. Gonzenbach, A. R. Studart, E. Tervoort, and L. J. Gauckler, "Macroporous Ceramics from Particle-Stabilized Wet Foams," J. Am. Ceram. Soc., 90 [1] 16-22 (2007)

${ }^{24}$ U. T. Gonzenbach, A. R. Studart, E. Tervoort, and L. J. Gauckler, "Tailoring the Microstructure of Particle-Stabilized Wet Foams," Langmuir, 23 [3] 1025-32 (2007).

${ }^{25}$ U. T. Gonzenbach, A. R. Studart, E. Tervoort, and L. J. Gauckler, "Ultrastable Particle-Stabilized Foams," Angew. Chem. Int., 45 [21] 2526-30 (2006).

${ }^{26}$ U. T. Gonzenbach, A. R. Studart, D. Steinlin, E. Tervoortand, and L. J. Gauckler, "Processing of Particle-Stabilized Wet Foams into Porous Ceramics," J. Am. Ceram. Soc., 90 [11] 3407-14 (2007).

${ }^{27}$ B. P. Binks, "Particles as Surfactants Similarities and Differences," Curr. Opin. Colloid Interf. Sci., 7, 21 (2002).

${ }^{28}$ S. Arditty, C. P. Whitby, B. P. Binks, V. Schmitt, and F. Leal-Calderon, "Some General Features of Limited Coalescence in Solid-Stabilized Emulsions," Eur. Phys. J. E., 11, 273 (2003).

${ }^{29}$ F. S. Ortega, P. Sepúlveda, M. D. M. Innocentini, and V. C. Pandolfelli, "Surfactants, a Necessity for Producing Porous Ceramics," Am. Ceram. Soc. Bull., 80 [4] 37-42 (2001). 